\title{
UNIVERSITYOF
}

FORWARD

THINKING

WESTMINSTER用

WestminsterResearch

http://www.westminster.ac.uk/westminsterresearch

\section{Electrospun Contrast Agent-Loaded Fibers for Colon-Targeted MRI}

Bligh, SWA., Jin, M., Yu, Deng-G., Wang, X., Geraldes, C.F.G.C. and Williams, Gareth R.

This is the peer reviewed version of the following article: Bligh, SWA., Jin, M., Yu, DengG., Wang, X., Geraldes, C.F.G.C. and Williams, Gareth R. (2016) Electrospun Contrast Agent-Loaded Fibers for Colon-Targeted MRI Advanced Healthcare Materials 21922659 , which has been published in final form at https://dx.doi.org/10.1002/adhm.201500872. This article may be used for noncommercial purposes in accordance with Wiley Terms and Conditions for Self-Archiving.

The WestminsterResearch online digital archive at the University of Westminster aims to make the research output of the University available to a wider audience. Copyright and Moral Rights remain with the authors and/or copyright owners.

Whilst further distribution of specific materials from within this archive is forbidden, you may freely distribute the URL of WestminsterResearch: ((http://westminsterresearch.wmin.ac.uk/)).

In case of abuse or copyright appearing without permission e-mail repository@westminster.ac.uk 


\section{Electrospun contrast agent-loaded fibers for colon-targeted MRI}

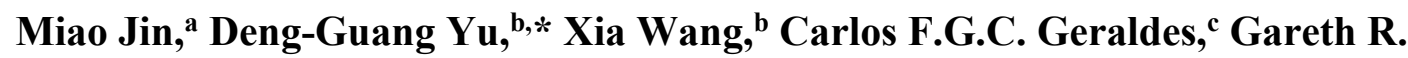 Williams, ${ }^{a}, *$ S.W. Annie Bligh ${ }^{\mathrm{d}, *}$}

Dr. M. Jin, Dr. G. R. Williams

UCL School of Pharmacy

University College London

29-39 Brunswick Square, London, WC1N 1AX, UK.

E-mail: g.williams@ucl.ac.uk

Prof. D. G. Yu, Prof. Xia Wang

School of Materials Science \& Engineering

University of Shanghai for Science and Technology, Shanghai 200093, China.

E-mail: ydg017@usst.edu.cn

Prof. C. F. G. C. Geraldes

Department of Life Sciences and Coimbra Chemistry Center - CQC

Faculty of Science and Technology, University of Coimbra, Coimbra, Portugal

Prof. S.W.A. Bligh

Faculty of Science and Technology

University of Westminster

115 New Cavendish Street, London, W1W 6UW, UK.

Email: a.bligh@westminster.ac.uk

Keywords: Gd(III) complex, colon-targeted delivery, coaxial electrospinning, core-shell fibers, magnetic resonance imaging

Magnetic resonance imaging (MRI) is a diagnostic tool used for detecting abnormal organs and tissues, often using $\mathrm{Gd}(\mathrm{III})$ complexes as contrast-enhancing agents. In this work, coreshell polymer fibers have been prepared using coaxial electrospinning, with the intent of delivering Gd(DTPA) (gadolinium (III) diethylenetriaminepentaacetate hydrate) selectively to the colon. The fibers comprise a poly(ethylene oxide) (PEO) core loaded with Gd(DTPA), and a Eudragit S100 shell. They are homogeneous, with distinct core-shell phases. The components in the fibers are dispersed in an amorphous fashion. The proton relaxivities of Gd(DTPA) are preserved after electrospinning. To permit easy visualization of the release of 
the active ingredient from the fibers, analogous materials were prepared loaded with the dye rhodamine B. Very little release is seen in a $\mathrm{pH} 1.0$ buffer, while sustained release is seen at $\mathrm{pH}$ 7.4. The fibers thus have the potential to selectively deliver Gd(DTPA) to the colon. Mucoadhesion studies revealed there are strong adhesive forces between porcine colon mucosa and PEO from the core, and the dye-loaded fibers can be successfully used to image the porcine colon wall. The electrospun core-shell fibers prepared in this work can thus be developed as advanced functional materials for effective imaging of colonic abnormalities.

\section{Introduction}

Gadolinium-based magnetic resonance imaging contrast agents are widely used in the clinic, but there are a number of potential side effects and limitations in terms of targeting. Free $\operatorname{Gd}(\mathrm{III})$ is nephrotoxic and neurotoxic, and hence much work has been done to ameliorate these issues. ${ }^{[1]}$ One solution is the use of Gd(III) chelates of high thermodynamic and kinetic stabilities, minimizing the release of free Gd(III) into solution. However, the use of some Gd(III) chelates (mostly with linear ligands) has been demonstrated to result in the severe complication of nephrogenic systemic fibrosis (NSF). ${ }^{[2]}$ The World Health Organization issued a restriction on the use of several gadolinium contrast agents in November 2009, stating that "High-risk gadolinium-containing contrast agents (Optimark, Omniscan, Magnevist, Magnegita and Gado-MRT ratiopharm) are contraindicated in some patients". [3]

To improve the safety of gadolinium-based MRI contrast agents, and additionally to increase their relaxivity or offer a longer time window for examination, a range of carrier systems such as dendrimers, ${ }^{[4]}$ steroids, ${ }^{[5]}$ micelles, ${ }^{[6]}$ or polymers ${ }^{[7]}$ conjugated or encapsulated with Gd(III) chelates have been studied. For instance, Cheng et al. demonstrated the utility of Gd(DTPA)-based dendrimer nanoclusters to detect folate receptor positive tumors in vivo and prolong the contrast agent circulation and residence times. ${ }^{[8]}$ In other work, Courant et al. reported that the conjugation of the Gd-DOTA complex (gadolinium (III) 
1,4,7,10-tetraazacyclododecane-1,4,7,10 tetraacetate, gadoterate meglumine, Dotarem ${ }^{\circledR}$ ) with polymeric nanoparticles (chitosan and hyaluronic acid) could reduce the risk of NSF and enhance relaxivity. ${ }^{[7]}$

Electrospinning is a simple technique which exploits electrical energy to prepare onedimensional nanoscale polymer fibers. ${ }^{[9]}$ A polymer solution is first prepared in a volatile solvent. It is then loaded into a syringe and expelled at a controlled rate through a metal needle (spinneret) towards a collector plate. A high voltage is applied between the spinneret and collector. The electrical energy thereby provided rapidly evaporates the solvent to yield polymer fibers. In the simplest experiment a single needle is used to prepare monolithic fibers, but it is also possible to design more complex experiments, for instance using a coaxial spinneret with one needle nested inside another. ${ }^{[10]}$ The latter results in core-shell fibers.

Electrospun fibers have been widely explored in a broad range of disciplines, including energy, environmental and photonic applications. ${ }^{[11]}$ In the biomedical field, they have attracted much attention as tissue scaffolds ${ }^{[12]}$ or drug delivery systems. ${ }^{[13]}$ The coaxial process offers a number of advantages over the single-fluid analogue in that it can broaden the range of materials which can be processed, ${ }^{[14]}$ or produce systems with functional components localized in different compartments of the fibers. ${ }^{[15]}$ To the best of our knowledge, no electrospun core-shell fibers have been investigated as contrast agent delivery systems to date.

In this work, we prepared Gd(DTPA) loaded fibers using a coaxial electrospinning process, with the aim of imaging colon abnormalities. This is currently a major clinical challenge, since contrast agents cannot readily be adsorbed by the colonic wall. ${ }^{[16]}$ At the present time, colon imaging by MRI involves the use of a nasoduodenal tube ${ }^{[17]}$ or rectal water enema. ${ }^{[18]}$ These routes are highly unpleasant for the patient. We thus sought here to develop an oral formulation for targeted delivery of $\operatorname{Gd}(\mathrm{DTPA})$ to the colon, in order to alleviate the discomfort experienced by patients requiring colonic MRI. The rationale behind our approach is illustrated in Figure 1. 
A pH-sensitive polymer (Eudragit S100, a methacrylic acid / methyl methacrylate copolymer which only dissolves at $\mathrm{pH}>7.0$ ) was used to form the fiber shells. The cores consisted of the bioadhesive polymer polyethylene oxide (PEO) loaded with Gd(DTPA). After oral administration, the Eudragit shell will prevent release of $\operatorname{Gd}(\mathrm{DTPA})$ as the formulation passes through the stomach and small intestine. Later, in the colon, the shell will dissolve to expose the core to the intestinal fluids. The PEO will absorb water, swell, and adhere to the colon walls. The presence of Gd(DTPA) in the core will permit the colon to be imaged by MRI.

\section{Results and discussion}

\subsection{Electrospinning}

Both PEO and Eudragit can be independently electrospun. Prior to preparing core-shell fibers, we optimized the electrospinning parameters for both the core and shell working fluids (see Supporting Information, Figures S1, S2 and S3). Subsequent to these experiments the shell fluid consisted of $13.5 \%$ Eudragit S100 (ES100) in a mixed solvent system of ethanol and DMAc (dimethylacetamide; 8:2 v/v), and the core fluid contained PEO and Gd(DTPA) (10:3 $\mathrm{w} / \mathrm{w})$ in ethanol/water $(7: 3 \mathrm{v} / \mathrm{v})$ with additives (acetone, $1 \% \mathrm{v} / \mathrm{v}$; Triton-X 100, $0.1 \% \mathrm{v} / \mathrm{v})$. Fibers were produced with a range of PEO molecular weights $(0.4 \mathrm{M}, 0.6 \mathrm{M}, 1 \mathrm{M}, 2 \mathrm{M}$ and 4 M), and with a variety of Gd(DTPA) loadings in the core.

Fourteen different core-shell fiber formulations were then prepared, as detailed in Table 1. Scanning electron microscopy (SEM) images of fibers F1 to F9 are shown in Figure 2a to 2i. All have linear morphologies and smooth surfaces without any beads-on-a-string phenomena. There is some influence of the PEO molecular weight (MW) on the fiber diameter, but no systematic trends can be seen in the data (Figure $\mathbf{2 j}$ ). The mechanism of electrospinning is extremely complicated and many factors influence the fiber diameters due to a complex interplay between fluid dynamics, electrodynamics and rheology. ${ }^{[19]}$ In order to prepare 
spinnable solutions it was necessary to reduce the solute content with increasing PEO MW; however, viscoelasticity is known to increase with MW. ${ }^{[10]}$ A balance of these two factors will be operational, and results in F3 having the largest fibers. In contrast, it is clear that increasing the Gd(III) complex loading with a constant PEO concentration leads to larger diameters (Figure 2k), as would be intuitively expected.

Transmission electron microscopy (TEM) images of F1 to F5 are depicted in Figure 3a to 3e. TEM images of F6 to F9 are shown in Figure S4. All have clear core-shell structures. The variations in shell and core size with the molecular weight of PEO used are given in Figure $3 \mathbf{f}$. As for the overall diameters, the core and shell sizes are the largest for F3.

\subsection{Physical form}

X-ray diffraction (XRD) and differential scanning calorimetry data on the various fibers are given in Figure S5. Gd(DTPA) and ES100 are amorphous materials: their XRD patterns contain no Bragg reflections, and the DSC data show no melting endotherms. A glass transition temperature can also be seen for ES100. The pure PEO fibers are semi-crystalline with characteristic diffraction peaks and melting transition at $61{ }^{\circ} \mathrm{C}$. All the coaxial fibers have amorphous structures, with no Bragg reflections visible by XRD, and no melting events present in their DSC traces (see Figure S5). This is in good agreement with previous studies on electrospun materials. ${ }^{[20]}$

The characteristic peaks of Gd(DTPA) and PEO in the IR spectra (Figure S6) of the coaxial fibers overlap with the ES100 peaks. However, it is notable that the peaks of the coaxial fibers at $1610 \mathrm{~cm}^{-1}$ are intensified in comparison to other peaks of ES100; this may be a result of the shift of the characteristic peaks of $\operatorname{Gd}(\mathrm{DTPA})$ from 1585 to $1610 \mathrm{~cm}^{-1}$. This indicates the formation of hydrogen bonds between the polymers and Gd(DTPA), suggesting that the fiber components have good compatibility. This is in agreement with the literature. ${ }^{[20]}$ 


\subsection{Proton relaxivities}

To ensure effective MRI imaging, it is vital that the Gd(III) complex is still able to function as a contrast agent post-electrospinning. This was assessed in terms of longitudinal and transverse relaxivities. The values recorded in a phosphate buffer (PBS; $\mathrm{pH} 7.4$ ) are listed in Table 2. Relaxivities, defined as the relaxation rate enhancements of water protons per $\mathrm{mM}$ concentration of the Gd(III) complex, were calculated by recording the longitudinal and transverse relaxation rates as a function of the concentration of contrast agent. The relaxivities of $\operatorname{Gd}(\mathrm{DTPA})$ can be seen to be lower in PBS than in water because of phosphate being exchanged with some of the water bound to Gd(III).

Compared with the values of the free complex, the physical mixtures generally exhibit slightly decreased relaxivities (see Table 2). This may result from weak interactions of the complexed Gd(III) with oxygen donor atoms from ether groups in PEO and carboxyl/carboxylate groups in ES100. The $r_{1}$ and $r_{2}$ values of Gd(DTPA) loaded fibers from single-fluid electrospinning present similar relaxivities $\left(r_{1}=4.00 \mathrm{~s}^{-1} \mathrm{mM}^{-1}, r_{2}=4.50 \mathrm{~s}^{-1} \mathrm{mM}^{-1}\right)$ to $\operatorname{Gd}(\mathrm{DTPA})$ in PBS buffer $\left(r_{1}=4.09 \mathrm{~s}^{-1} \mathrm{mM}^{-1}, r_{2}=4.67 \mathrm{~s}^{-1} \mathrm{mM}^{-1}\right)$. The small differences could result from the different concentration of PEO present in the PBS buffer $(0.5 \% \mathrm{w} / \mathrm{v}$ PEO for the physical mixture and $0.16 \% \mathrm{w} / \mathrm{v}$ for single-fluid fibers), but in any case has very little effect on the relaxivities.

For the core-shell fibers, the average relaxivities across all the fibers are $r_{1}=4.27 \mathrm{~s}^{-1} \mathrm{mM}^{-1}$, $r_{2}=6.99 \mathrm{~s}^{-1} \mathrm{mM}^{-1}$. These are somewhat different to the values for Gd(DTPA) in PBS, as the accessibility of the $\mathrm{Gd}(\mathrm{III})$ chelate to bulk water and its mobility may be affected by the presence of both ES100 and PEO (ca. $2.2 \% \mathrm{w} / \mathrm{v}$ totally). Although there are small differences in the relaxivities of $\operatorname{Gd}(\mathrm{DTPA})$ in the fibers compared to the free complex, it is clear that processing by electrospinning has a minimal effect on the relaxivity. Thus, the formulations prepared in this work are expected to be as effective as pure Gd(DTPA) at MR imaging. The results obtained here also show that there is minimal release of free Gd(III) from Gd(DTPA): 
free Gd(III), besides its high toxicity, has high affinity with phosphate which can give rise to negligible relaxivities. ${ }^{[21]}$ The thermodynamic and kinetic stability of the complex thus remain high after they have been incorporated into fibers by electrospinning.

To mitigate any adverse effects from the phosphate present in PBS, relaxivities were also measured in tris buffer ( $\mathrm{pH}$ 7.4). The values obtained are given in Table 3. In tris buffer, the relaxivities of $\operatorname{Gd}(\mathrm{DTPA})$ are almost identical to those in water, because the nitrogen atom donor in tris has minimal interaction with the Gd(III) complex. Therefore, the tris buffer has even less effect on Gd(DTPA) relaxivity than the PBS buffer. The $r_{1}$ and $r_{2}$ values of a physical mixture $(0.5 \% \mathrm{w} / \mathrm{v}$ PEO and $1 \mathrm{mM} \mathrm{Gd(DTPA}))$ and the monolithic fibers $\left(r_{1}=4.37\right.$ $\mathrm{s}^{-1} \mathrm{mM}^{-1}, r_{2}=4.79 \mathrm{~s}^{-1} \mathrm{mM}^{-1}$ ) are close to those of the Gd(III) DTPA complex in tris buffer. For the physical mixture of all three fiber components there is a relaxivity enhancement, believed to arise from the tris bridging between ES100/PEO and Gd(DTPA) through hydrogen bonding and electrostatic interactions. As a result, the coaxial fibers (average $r_{1}=8.86 \mathrm{~s}^{-1} \mathrm{mM}^{-1}, r_{2}=$ $12.49 \mathrm{~s}^{-1} \mathrm{mM}^{-1}$ ) display similarly increased relaxivities.

Signal intensity in MRI depends to a large extent on the value of the longitudinal relaxation rate of water protons, $1 / T_{1}$, and the transverse rate, $1 / T_{2}$. When longitudinal relaxivity values $\left(r_{1}\right)$ show an upward tendency, signal intensities tend to be greater. In contrast, increasing transverse relaxivity $\left(r_{2}\right)$ is always associated with signal loss. ${ }^{[22]}$ The ratio of $r_{2} / r_{1}$ for the coaxial materials dissolved in tris buffer ranges from $1.15-1.77$ ( $c f .1 .11$ for $\operatorname{Gd}(\mathrm{DTPA})$ ). Contrast agents with small $r_{2} / r_{1}$ values are found to be efficient as $T_{1}$ MRI contrast agents. ${ }^{[23]}$ Similar values of $r_{2} / r_{1}(1.4)$ were reported for $\mathrm{Gd}_{2} \mathrm{O}_{3}$ nanoparticles stabilized by polyethylene glycol (PEG), which were also reported to have two-fold higher relaxivity than Gd(DTPA). ${ }^{[24]}$ The incorporation of Gd(DTPA) into an electrospun fiber clearly did not alter its ability as a contrast agent, and hence the formulations prepared in this work should be potent in vivo. 


\subsection{In vitro release and swelling}

To be maximally effective for colon MRI, it is important that the Gd(DTPA) in the fibers is carried to the colon, and not released in the stomach. Thus, dissolution tests were performed. These showed only very small amounts of release at $\mathrm{pH} 1.0$, but the accurate quantification of Gd(DTPA) during these experiments was challenging: the concentrations of Gd present were very close to the detection limit of the instrument. In order to validate the fact that minimal release occurred at $\mathrm{pH}$ 1.0, we prepared analogous fibers to F3 but loaded with rhodamine $\mathrm{B}$ in place of Gd(DTPA) in the core (F10; see Figure 4). Rhodamine B is a dye with similar molecular weight $(479.02 \mathrm{~g} / \mathrm{mol})$ to $\mathrm{Gd}(\mathrm{DTPA})(565.59 \mathrm{~g} / \mathrm{mol})$. It has a very high extinction coefficient $\left(87,000 \mathrm{~cm}^{-1} \mathrm{M}^{-1}\right)$ at $554 \mathrm{~nm}$, allowing any release to be easily visualized. ${ }^{[25]}$

The F10 fibers are smooth with average diameter of $0.63 \pm 0.26 \mu \mathrm{m}$ (Figure 4a) and two distinct phases (Figure 4b). For the first two hours of the dissolution experiment, the F10 fibers were immersed in a $\mathrm{pH} 1.0$ dissolution medium. Very little rhodamine B release was detected as a result of this incubation. The fibers showed a typical sustained release profile when they were placed into a neutral dissolution medium as they gradually absorbed water, swelled, dissolved and disappeared (see Figure S7). This finding generally agrees with data from the swelling studies (F10 swelled by $1050 \%$ after $4 \mathrm{~h}$ immersion in PBS; see Figure S8).

The amount of Gd(DTPA) which could be recovered from $c a .150 \mathrm{mg}$ of F1 - F9 after analogous dissolution tests ranges from 1.35 to $9.69 \mu \mathrm{mol}$ (see Table S1). The highest loading materials thus contain comparable amounts of the Gd(III) complex to clinically used preparations of Magnevist, where typically 7.5 to $10 \mu \mathrm{mol}$ of Gd(DTPA) is found to be highly accurate for colorectal lesion detection using magnetic resonance colonoscopy. ${ }^{[26]}$ For the majority of the fibers, a dose of $<500 \mathrm{mg}$ would provide sufficient $\mathrm{Gd}$ (III) complex for effective imaging. The highest loading material (F9) could be used at doses of $0.2 \mu \mathrm{mol} / \mathrm{kg}$, far smaller than the clinical intravenous dose of $100 \mu \mathrm{mol} / \mathrm{kg}$ currently used, ${ }^{[27]}$ which could reduce the risk of toxicity. ES100 and PEO are approved by the US Food and Drug 
Administration, ${ }^{[28]}$ and are commonly used as pharmaceutical excipients for the development of oral dosage forms such as tablets ${ }^{[29]}$ and films. ${ }^{[30]}$ Therefore, after the oral administration of the fibers, we can be confident that they will have no toxic effects.

\subsection{Mucoadhesion}

From the data shown so far, it is demonstrated that Gd(DTPA) loaded into core-shell fibers retains its MRI properties after electrospinning, and that the ES100 shell can effectively prevent its release in the stomach. The PEO core swells extensively in a colon-mimicking environment, ${ }^{[31]}$ and as it does so Gd(DTPA) is freed. It is also crucial that the PEO core has mucoadhesive properties so that it can attach to the wall of the colon, delivering the Gd(DTPA) specifically to this location. Mucoadhesive properties were measured in terms of the force required to detach the fibers from porcine mucosa. The mucoadhesion properties of PEO fibers from single-fluid electrospinning are given in Figures $\mathrm{S} 9$ and $\mathbf{4 c}$. The high molecular weight PEO 1M shows the highest adhesion force of all the PEO materials. This agrees with the literature, in which the mucoadhesive properties of PEO have been reported to depend on the molecular weight and chain length of the polymer. ${ }^{[32]}$

In order to improve the retention time in the colon, the core of the fibers must still possess mucoadhesive properties after the dissolution of the shell layer. F10 (Eudragit/PEOrhodamine B) was thus placed in a PBS buffer for different periods of time to explore how mucoadhesion is affected. Although the adhesion forces are lower than those of the monolithic analogue, F10 still has a high adhesion force after immersion for $1 \mathrm{~h}$ in a PBS buffer (Figure 4c). After prolonged periods of exposure to the $\mathrm{pH} 7.4$ buffer, the mucoadhesive performance of F10 remains roughly constant, which suggests the fibers would stick to the wall of the colon for at least $4 \mathrm{~h}$. 
To ensure that these findings are broadly applicable, further rhodamine B-loaded fibers made from different MW PEOs were prepared (see Table 1 and Figure S10). These were similarly found to be able to adhere to the colonic mucosa for at least 4 h (see Figure S11).

\subsection{In vitro porcine colon imaging}

For successful formulations, it is vital that they both mucoadhere and also are able to transfer their functional ingredient to the mucosa. After the mucoadhesion studies, the colon sections tested were photographed under UV light in order to check for dye adsorption on the colonic mucosa. The results for F10 are presented in Figure 4d. No dye can be seen on the colonic mucosa after $2 \mathrm{~h}$ in $\mathrm{HCl}$. After exposure to a $\mathrm{pH} 7.4$ medium however, rhodamine $\mathrm{B}$ dye can be clearly observed on the surface of the colon. This arises due to the adhesive ability of PEO, which sticks to the mucosa and holds the rhodamine B in place on its surface. Similar results were found for additional formulations made from different PEO MW (F11-F14; see Figure S12).

Finally, experiments were performed to see whether the F10 fibers could be used to image the porcine colon in conditions designed to mimic those in vivo. The F10 fibers were initially immersed in $0.1 \mathrm{~N} \mathrm{HCl}$, before being further incubated in $\mathrm{pH} 7.4 \mathrm{PBS}$ for different time periods. The Eudragit shell dissolves in the PBS buffer, and the exposed rhodamine B-loaded PEO cores were subsequently removed from the PBS medium and placed on the mucosal side of a segment of porcine colon (either immediately or after being allowed to dry) and left to incubate at $37{ }^{\circ} \mathrm{C}$ under rotation (simulating gastric movements). Images taken under a UV lamp are given in Figure 5. The intensity of fluorescence from the dye, for both the dried and still-wet fibers, was much stronger than the control (a rhodamine B solution) after incubation

for 1,2 or $4 \mathrm{~h}$. This can be attributed to the ability of PEO to adhere to the mucosa. ${ }^{[33]}$ The longer the fibers were left on the colon, the more intense the fluorescence intensity was seen to be. Immersing the fibers in a $\mathrm{pH} 7.4$ buffer for $2 \mathrm{~h}$ before adding them to the colon led to 
stronger fluorescence intensity than an immersion time of $1 \mathrm{~h}$. This can be explained because a longer PBS incubation time leads to a greater the amount of the ES100 shell dissolving, and thus more of the core surface area being exposed.

Both dry and hydrated composite fibers show good imaging properties (Figure 5a and b) and no signs of damage to the colonic tissue can be observed. The dry fibers absorbed water from the mucosal membrane (this is present because of low fluid volumes in the colon), ${ }^{[34]}$ permitting the mucoadhesive properties of the PEO to be activated and contributing to close contact between the fibers and the mucosa. ${ }^{[35]}$ The wet fibers are capable of adhering to the mucus layers without needing to take up water from them. ${ }^{[36]}$ To validate our findings with S10, the fibers F11 - F14 (containing rhodamine B-loaded cores of different MW PEOs) were also explored in these assays, with analogous results being observed (Figure S12).

\section{Conclusions}

Core-shell fibers for MRI were successfully produced by coaxial electrospinning. The shell of the fibers comprised Eudragit S100, while the core was made up of PEO loaded with Gd(DTPA). Analogous fibers loaded with rhodamine B for fluorescence imaging were also prepared. The characterizing data indicated a homogenous and amorphous dispersion of Gd(DTPA) in the fiber products, and showed that high quality fibers with smooth cylindrical morphologies and clear core-shell compartments can be produced. The proton relaxivities for Gd(DTPA) released from the fibers were similar to those of the complex in PBS buffer. In addition, all the coaxial materials in tris buffer gave increased relaxivities (average $r_{1}=8.86$ and $\left.r_{2}=12.49 \mathrm{~s}^{-1} \mathrm{mM}^{-1}\right)$ compared with the free complex $\left(r_{1}=4.37 \mathrm{~s}^{-1} \mathrm{mM}^{-1}\right.$ and $r_{2}=4.85 \mathrm{~s}^{-1} \mathrm{mM}^{-}$ ${ }^{1}$ ). Very little release of either Gd(DTPA) or rhodamine B was found at $\mathrm{pH} 1.0$, while sustained release was attained at $\mathrm{pH}$ 7.4. The mucoadhesive properties of the fibers were measured in vitro on porcine colonic mucosa, and the core-shell fibers were found to have strong adhesion forces after dissolution of the Eudragit shell. Proof-of-concept imaging 
experiments showed that the fibers could effectively transfer rhodamine B to the colonic mucosa, permitting it to be imaged via the fluorescent properties of the dye. The simple and straightforward approach to prepare colon-targeted MRI agent delivery systems explored in this work thus offers a new technique to permit effective imaging of colonic abnormalities through the use of electrospun systems.

\section{Experimental Section}

Materials: Diethylenetriaminepentaacetic acid gadolinium(III) hydrate Gd(DTPA) and rhodamine B were purchased from Sigma-Aldrich UK. Eudragit S100 (MW 125,000 g/mol) was obtained from Evonik GmbH. Polyethylene oxide materials were provided by SigmaAldrich UK (MW=0.4 MDa), Acros Organics UK (MW=0.6 MDa) and Colorcon Ltd (MW=1, 2, $4 \mathrm{MDa}$ ). Anhydrous ethanol used for dissolving the polymers was analytical grade (Fisher Scientific, UK). Triton X 100 and dimethylacetamide (DMAc) were supplied by SigmaAldrich UK. All water used was deionised.

Preparation of solutions for single-fluid electrospinning: Eudragit S100 was dissolved in $10 \mathrm{ml}$ of ethanol or a solvent system comprising ethanol and DMAc (8:2 v/v) with a concentration of $11 \%$ or $13.5 \%$ w/v. Pure PEOs (MW $=400,600,1000,2000$ and 4000k Da) were dissolved in mixtures of ethanol and water $(7: 3 \mathrm{v} / \mathrm{v})$ with additives $(1 \% \mathrm{v} / \mathrm{v}$ acetone and $0.1 \% \mathrm{v} / \mathrm{v}$ Triton $\mathrm{X} 100)$. A PEO solution $(\mathrm{Mw}=1000 \mathrm{k} \mathrm{Da})$ containing a $30 \%$ loading of Gd(DTPA) (with respect to the weight of PEO 1M) was also prepared in ethanol/water $(10 \mathrm{ml})$ with the acetone and Triton additives.

Preparation of Gd(III) complex loaded spinning solutions for coaxial electrospinning: The concentration of the shell solution (Eudragit S100) was kept at $13.5 \% \mathrm{w} / \mathrm{v}$ in ethanol/DMAc $(8: 2 \mathrm{v} / \mathrm{v})$. PEO core solutions $(\mathrm{MW}=0.4,0.6,1,2,4 \mathrm{MDa})$ containing varied $\mathrm{Gd}(\mathrm{DTPA})$ (rhodamine B) contents (see Table 1) were prepared in a mixture of ethanol and water $(7: 3$ $\mathrm{v} / \mathrm{v})$ with additives $(1 \% \mathrm{v} / \mathrm{v}$ acetone and $0.1 \% \mathrm{v} / \mathrm{v}$ Triton $\mathrm{X} 100)$. 
Electrospinning: A high voltage power supply (HCP 35-35000, FuG Elektronik GmbH, Rosenheim, Germany) was employed to provide electrical energy. A crocodile clip (the positive electrode) was attached to a stainless steel capillary needle (inside diameter of 0.5 $\mathrm{mm}$ ). The spinning solution was loaded in a $10 \mathrm{ml}$ or $20 \mathrm{ml}$ syringe and the spinneret was attached. Great care was taken to avoid bubbles. The grounded electrode was connected to a flat metal collector wrapped with aluminum foil. The electrospinning process was undertaken under ambient conditions $\left(22 \pm 3{ }^{\circ} \mathrm{C}\right.$ and relative humidity $\left.30 \pm 5 \%\right)$. Temperature and humidity were monitored throughout experiments using a digital thermometer/hydrometer, and electrospinning only undertaken when the environmental conditions were appropriate. For single fluid electrospinning, a syringe pump (KDS 100, Cole-Parmer) was used to control the flow rate of the solutions, at $0.5 \mathrm{ml} \mathrm{h}^{-1}$ for PEO solutions or $1 \mathrm{ml} \mathrm{h}^{-1}$ for ES100. The voltage was fixed at $9 \mathrm{kV}$ for PEO spinning and $11 \mathrm{kV}$ for Eudragit, with a vertical distance of $15 \mathrm{~cm}$ between the tip and the collector for PEO and $20 \mathrm{~cm}$ for Eudragit. For coaxial electrospinning, two syringe pumps (KDS 100, Cole-Parmer) were employed to control the shell $\left(1.5 \mathrm{ml} \mathrm{h}^{-1}\right)$ and the core flow $\left(0.3 \mathrm{ml} \mathrm{h}^{-1}\right)$ rates. The voltage was fixed at $11 \mathrm{kV}$, with a distance of $20 \mathrm{~cm}$ from the needle tip to the collector. A home-made concentric spinneret was prepared by inserting a small stainless steel needle $(27 \mathrm{G}$; outer and inner diameters of 0.42 and $0.21 \mathrm{~mm}$, respectively) into a larger needle (18G; outer and inner diameters of 1.25 and $0.84 \mathrm{~mm}$ ).

In vitro dissolution: In vitro dissolution tests were carried out in a mini paddle dissolution apparatus (Model PTWS, Pharma Test). The fibers (ca. $150 \mathrm{mg}$ ) were placed in $0.1 \mathrm{~N} \mathrm{HCl}$ $(150 \mathrm{ml})$ for $2 \mathrm{~h}$ and subsequently transferred to phosphate buffered saline (150 ml; PBS; pH 7.4) at $37{ }^{\circ} \mathrm{C}$. The medium was stirred at a constant speed of $50 \mathrm{rpm}$ under sink conditions. 5 $\mathrm{ml}$ samples were withdrawn from the dissolution medium at predetermined time points, and replaced by $5 \mathrm{ml}$ fresh medium. F1-F9 and F10 were analysed using microwave plasmaatomic emission spectroscopy (4100 MP-AES instrument, Agilent Technologies) and UV-vis 
spectrophotometer (7315 Spectrophotometer, Jenway) respectively. Each experiment was repeated three times, and results are reported as mean \pm S.D.

Tissue preparation: Large intestines were obtained from three pigs and kept in ice after slaughtering (supplier: Cheale Meats Ltd, UK). The intestine was washed carefully with physiological saline solution $(0.9 \% \mathrm{w} / \mathrm{v} \mathrm{NaCl})$ to remove non-digested food. Samples were frozen at $-80{ }^{\circ} \mathrm{C}$ until their use for mucoadhesion and imaging experiments.

Mucoadhesion experiments: Mucoadhesion was assessed using a tensile strength method (Instron). Frozen large intestine was defrosted slowly at $10{ }^{\circ} \mathrm{C}$ overnight to minimize damage to the mucosa. Subsequently samples were allowed to warm to room temperature before being further warmed to $37{ }^{\circ} \mathrm{C}$ in a water bath. The porcine colons were not subjected to prehydration in order to preserve the natural moist environment of their mucosa. Samples of the mucosa (approximately $4 \mathrm{~cm}^{2}$ ) were cut and placed on a petri dish. A cylindrical home-made HDPE (high density polyethylene) adaptor (height: $10 \mathrm{~mm}$; diameter: $10 \mathrm{~mm}$ ) was attached to the probe of the tensile tester using double-sided tape. The surface of the HDPE adaptor was next covered with the fiber sample under test, with the fibers secured to the adaptor using double-sided tape. The fiber-covered adaptor was moved down towards the porcine colonic mucosa at a constant speed of $10 \mathrm{~mm} \mathrm{~min}^{-1}$, and a compressive force of $0.5 \mathrm{~N}$ was applied for a predetermined time (30 seconds for PEO single-fluid fibers (to avoid their dissolution in the moist environment of the mucosa), 5 minutes for the coaxial fibers to allow the fibers to contact with the mucosa effectively). The adaptor was then pulled away from the mucosa at a constant speed of $20 \mathrm{~mm} \mathrm{~min}^{-1}$. The mucoadhesive properties were evaluated in terms of the energy at break, defined as the work of adhesion. ${ }^{[37]}$ Each fiber sample was measured once on a given portion of mucosa and each batch of the fibers was tested three times. The fibers prepared through single-fluid electrospinning were attached to the adaptor directly. The coaxial fibers were first subjected to a dissolution stage $(2 \mathrm{~h}$ in an acidic solution $(0.1 \mathrm{~N} \mathrm{HCl})$, 
then $1 \mathrm{~h}, 2 \mathrm{~h}$, or $4 \mathrm{~h}$ in a $\mathrm{pH} 7.4 \mathrm{PBS}$ buffer), retrieved from the medium and dried at room temperature before measurement.

Imaging experiments: $5 \mathrm{mg}$ of the core / shell fibers loaded with rhodamine B were placed in sealed vials with a $\mathrm{pH} 7.4$ PBS buffer $(5 \mathrm{ml})$ and incubated in a water bath at $37^{\circ} \mathrm{C}$ for a predetermined time ( $1 \mathrm{~h}$ and $2 \mathrm{~h}$ respectively) in order to remove the Eudragit shell. Specimens were either i) removed from the vials and dried in an oven at $37^{\circ} \mathrm{C}$ overnight prior to its placement on the colon, or ii) removed from the vials and directly incubated with porcine colon. The fibers were transferred to a $4 \mathrm{~cm}^{2}$ piece of colon (mucosa side) fixed on an Ussing chamber. The samples were left to incubate at $37^{\circ} \mathrm{C}$ at a rotation speed of $80 \mathrm{rpm}$ for a certain period of time (1,2 or $4 \mathrm{~h})$. This is to ensure adhesion between the mucosa and the fibers by mimicking the motion of the porcine colon. After incubation, the tubular colon was unfolded and washed with $5 \mathrm{ml}$ PBS buffer. Finally, the colon was cut and photographs were taken under UV light. As a control, a $50 \mathrm{ppm}$ solution of rhodamine B (180 $\mu \mathrm{l})$ was incubated with the colonic mucosa for each time point.

Electron microscopy: The morphology of the fibers was examined using scanning electron microscopy (SEM; FEI Quanta 200 FEG ESEM, FEI Corporation). Samples were gold sputter-coated under an argon atmosphere before assessment. Images were then recorded with an excitation voltage of $5-10 \mathrm{kV}$. The diameters of the fibers were measured at more than 100 points in SEM images using the Image $J$ software (National Institutes of Health) to determine the average size. Transmission electron microscopy images of the specimens were taken using a Philips CM 120 Bio-Twin instrument (Philips/FEI Corporation).

Physical form assessment: Differential scanning calorimetry (DSC) analyses were performed using a Q2000 instrument (TA Instruments). Specimens in sealed and pinholed pans were heated from 0 to $180{ }^{\circ} \mathrm{C}$ (Eudragit fibers), $130{ }^{\circ} \mathrm{C}$ (PEO fibers) or $180{ }^{\circ} \mathrm{C}$ (coaxial fibers) at $10^{\circ} \mathrm{C} \mathrm{min}^{-1}$ under a flow of nitrogen gas $\left(50 \mathrm{ml} \mathrm{min}{ }^{-1}\right)$. X-ray diffraction (XRD) patterns were recorded over the $2 \theta$ range from 10 to $60^{\circ}$ on a Rigaku MiniFlex 600 instrument 
using $\mathrm{Cu} \mathrm{K \alpha}$ radiation at $40 \mathrm{kV}$ and $15 \mathrm{~mA}$. Fourier transform infrared (FTIR) analyses were carried out on a Spectrum 100 instrument (PerkinElmer) over the range $650-4000 \mathrm{~cm}^{-1}$ at a resolution of $4 \mathrm{~cm}^{-1}$.

Microwave plasma-atomic emission spectroscopy: The $\mathrm{Gd}$ concentration in the release media was determined by microwave plasma-atomic emission spectroscopy (4100 MP-AES instrument, Agilent Technologies). Three samples (ca. $10 \mathrm{mg} /$ sample) for each fiber were prepared and digested in $5 \mathrm{~cm}^{3}$ tris buffer separately. The measurements for each sample were repeated three times and recorded using the Gd(II) lines at $376.8 \mathrm{~nm}$ and $409.8 \mathrm{~nm}$.

Proton relaxivities: The longitudinal $\left(T_{1} ; 20\right.$ data points $)$ and transverse relaxation times $\left(T_{2}\right.$; 400 data points) of water protons were recorded on a Minispec mq20 relaxometer $(20 \mathrm{MHz}$, $0.47 \mathrm{~T}$, Bruker Corporation) at $37^{\circ} \mathrm{C}$, using inversion recovery and $\mathrm{CPMG}$ pulse sequences, respectively. A solution (in PBS or tris buffer) of the fibers with $0.25,0.5,0.75$ and $1 \mathrm{mM}$ $\mathrm{Gd}(\mathrm{III})$ concentration was loaded in a $10 \mathrm{~mm}$-diameter NMR tube and warmed to $37^{\circ} \mathrm{C}$ in a water bath prior to measurement. Each sample was measured three times.

\section{Supporting Information}

Supporting Information is available from the Wiley Online Library or from the author.

\section{Acknowledgements}

This work was supported by the China NSFC/UK Royal Society cost share international exchanges scheme (No. 51411130128/IE131748) and the National Science Foundation of China (No. 51373101). CFGCG thanks the FCT-Portugal (Portuguese Foundation for Science and Technology) and FEDER-European Regional Development Fund through the COMPETE Programme (Operational Programme for Competitiveness) for funding (UID/QUI/00313/2013 and PEst-OE/QUI/UI0313/2014).

Received: ((will be filled in by the editorial staff))

Revised: ((will be filled in by the editorial staff)) Published online: ((will be filled in by the editorial staff))

\section{References}

[1] a) F. Chen, W. Bu, S. Zhang, J. Liu, W. Fan, L. Zhou, W. Peng and J. Shi, Adv. Funct. Mater. 2013, 23, 298-307; b) C. F. Geraldes and S. Laurent, Contrast Media Mol. Imaging 
2009, 4, 1-23; c) H. J. Lee, Y. H. Park and W. G. Koh, Adv. Funct. Mater. 2013, 23, 591-597;

d) I. Marangon, C. Ménard Moyon, J. Kolosnjaj Tabi, M. L. Béoutis, L. Lartigue, D. Alloyeau, E. Pach, B. Ballesteros, G. Autret and T. Ninjbadgar, Adv. Funct. Mater. 2014, 24, 7173-7186; e) H. Yang, C. Qin, C. Yu, Y. Lu, H. Zhang, F. Xue, D. Wu, Z. Zhou and S. Yang, Adv. Funct. Mater. 2014, 24, 1738-1747.

[2] P. Marckmann, L. Skov, K. Rossen, A. Dupont, M. B. Damholt, J. G. Heaf and H. S. Thomsen, J. Am. Soc. Nephrol. 2006, 17, 2359-2362.

[3] a) E. Kanal, A. J. Barkovich, C. Bell, J. P. Borgstede, W. G. Bradley Jr, J. W. Froelich, T. Gilk, J. R. Gimbel, J. Gosbee and E. Kuhni-Kaminski, Am. J. Roentgenol. 2007, 188, 14471474; b) W. H. Organization, Pharmaceuticals: Restrictions in Use and Availability World Health Organization 2010, p 14.

[4] a) M. Ye, Y. Qian, J. Tang, H. Hu, M. Sui and Y. Shen, J. Controlled Release 2013, 169, 239-245; b) W. C. Floyd, III, P. J. Klemm, D. E. Smiles, A. C. Kohlgruber, V. C. Pierre, J. L. Mynar, J. M. J. Frechet and K. N. Raymond, J. Am. Chem. Soc. 2011, 133, 2390-2393.

[5] J. Lee, M. J. Zylka, D. J. Anderson, J. E. Burdette, T. K. Woodruff and T. J. Meade, J. Am. Chem. Soc. 2005, 127, 13164-13166.

[6] a) P. Mi, H. Cabral, D. Kokuryo, M. Rafi, Y. Terada, I. Aoki, T. Saga, I. Takehiko, N. Nishiyama and K. Kataoka, Biomaterials 2012, 34, 492-500; b) M. Grogna, R. Cloots, A. Luxen, C. Jerome, C. Passirani, N. Lautram, J.-F. Desreux and C. Detrembleur, Polym. Chem. 2010, $1,1485-1490$.

[7] T. Courant, V. G. Roullin, C. Cadiou, M. Callewaert, M. C. Andry, C. Portefaix, C. Hoeffel, M. C. de Goltstein, M. Port, S. Laurent, L. Vander Elst, R. Muller, M. Molinari and F. Chuburu, Angew. Chem., Int. Ed. 2012, 51, 9119-9122.

[8] Z. Cheng, D. L. J. Thorek and A. Tsourkas, Angew. Chem., Int. Ed. 2010, 49, 346-350.

[9] A. Greiner and J. H. Wendorff, Angew. Chem., Int. Ed. 2007, 46, 5670-5703.

[10] A. K. Moghe and B. S. Gupta, Polym. Rev. 2008, 48, 353-377. 
[11] a) S. Agarwal, A. Greiner and J. H. Wendorff, Prog. Polym. Sci. 2013, 38, 963-991; b) G. Morello, M. Moffa, S. Girardo, A. Camposeo and D. Pisignano, Adv. Funct. Mater. 2014, 24, 5225-5231; c) Y. Zhang, J. J. Kim, D. Chen, H. L. Tuller and G. C. Rutledge, Adv. Funct. Mater. 2014, 24, 4005-4014; d) Z. Zhang, M. J. Gupte, X. Jin and P. X. Ma, Adv. Funct. Mater. 2015, 25, 350-360.

[12] a) W. Y. Liu, S. Thomopoulos and Y. N. Xia, Adv. Healthcare Mater. 2012, 1, 10-25; b)

F. Croisier, G. Atanasova, Y. Poumay and C. Jerome, Adv. Healthcare Mater. 2014, 3, 20322039; c) H. Xu, W. G. Cui and J. Chang, J. Appl. Polym. Sci. 2013, 127, 1550-1554.

[13] a) Y. J. Kim, M. Ebara and T. Aoyagi, Adv. Funct. Mater. 2013, 23, 5753-5761; b) D. Yu, X. Wang, X. Li, W. Chian, Y. Li and Y. Liao, Acta Biomater. 2013, 9, 5665-5672; c) W. G. Cui, Y. Zhou and J. Chang, Sci. Technol. Adv. Mater. 2010, 11; d) M. L. Chen, Y. F. Li and F. Besenbacher, Adv. Healthcare Mater. 2014, 3, 1721-1732.

[14] a) J. E. Díaz, A. Barrero, M. Márquez and I. G. Loscertales, Adv. Funct. Mater. 2006, 16, 2110; b) J. H. Yu, S. V. Fridrikh and G. C. Rutledge, Adv. Mater. 2004, 16, 1562-1566.

[15] D.-G. Yu, K. White, N. Chatterton, Y. Li, L. Li and X. Wang, RSC Adv. 2015, 5, 94629466.

[16] J. Sun, W. Zheng, H. Zhang, T. Wu, H. Yuan, X. Yang and S. Zhang, Magn. Reson. Med. 2011, 65, 673-679.

[17] I. J. M. Han-Geurts, W. C. Hop, C. Verhoef, K. T. C. Tran and H. W. Tilanus, Br. J. Surg. 2007, 94, 31-35.

[18] G. S. Gazelle, J. Gaa, S. Saini and P. Shellito, J Comput Assist Tomogr. 1995, 19, 87-91.

[19] S. Ramakrishna, K. Fujihara, W.-E. Teo, T.-C. Lim and Z. Ma, An Introduction to Electrospinning and Nanofibers, World Scientific Publishing Co. Pte. Ltd., Singapore, 2005, p. 63-74. 
[20] a) Y.-N. Jiang, H.-Y. Mo and D.-G. Yu, Int. J. Pharm. 2012, 438, 232-239; b) X. Shen,

D. Yu, L. Zhu, C. Branford-White, K. White and N. P. Chatterton, Int. J. Pharm. 2011, 408, 200-207.

[21] A. D. Sherry, P. Caravan and R. E. Lenkinski, J. Magn. Reson. Imaging 2009, 30, 12401248.

[22] P. Caravan, J. J. Ellison, T. J. McMurry and R. B. Lauffer, Chem. Rev. 1999, 99, 22932352.

[23] H. B. Na and T. Hyeon, J. Mater. Chem. 2009, 19, 6267-6273.

[24] F. Marc-André, M. P. Rodrigo, Jr., S. Fredrik, A. Klasson, E. Maria, V. Teodor, K. PerOlof and U. Kajsa, Nanotechnol. 2007, 18, 395501.

[25] a) A. A. M. Farag and I. S. Yahia, Opt. Commun. 2010, 283, 4310-4317; b) E. Birtalan, B. Rudat, D. K. Koelmel, D. Fritz, S. B. L. Vollrath, U. Schepers and S. Braese, Biopolymers 2011, 96, 694-701.

[26] G. Pappalardo, E. Polettini, F. M. Frattaroli, E. Casciani, C. D'Orta, M. D'Amato and G. F. Gualdi, Gastroenterology 2000, 119, 300-304.

[27] K. L. Nelson, L. M. Gifford, C. Lauber-Huber, C. A. Gross and T. A. Lasser, Radiology 1995, 196, 439-443.

[28] a) A. H. El-Kamel, M. S. Sokar, S. S. Al Gamal and V. F. Naggar, Int. J. Pharm. 2001, 220, 13-21; b) P. P. Ghoroghchian, G. Z. Li, D. H. Levine, K. P. Davis, F. S. Bates, D. A. Hammer and M. J. Therien, Macromolecules 2006, 39, 1673-1675.

[29] a) R. V. Kumar and V. R. Sinha, Acta Pharm. 2011, 61, 343-351; b) S. Shojaee, I. Cumming, W. Kaialy and A. Nokhodchi, Colloids Surf., B 2013, 111, 486-492.

[30] A. Akhgari, F. Farahmand, H. A. Garekani, F. Sadeghi and T. F. Vandamme, Eur. J. Pharm. Sci. 2006, 28, 307-314.

[31] A. Apicella, B. Cappello, M. A. Del Nobile, M. I. La Rotonda, G. Mensitieri and L. Nicolais, Biomaterials 1993, 14, 83-90. 
[32] P. K. Gupta, S.-H. S. Leung and J. R. Robinson, Bioadhesive Drug Delivery Systems 1990, 65-92.

[33] J. D. Smart, Adv. Drug Delivery Rev. 2005, 57, 1556-1568.

[34] C. Schiller, C. P. FrÖHlich, T. Giessmann, W. Siegmund, H. MÖNnikes, N. Hosten and W. Weitschies, Aliment. Pharmacol. Ther. 2005, 22, 971-979.

[35] F. J. O. Varum, F. Veiga, J. S. Sousa and A. W. Basit, Eur. J. Pharm. Sci. 2010, 40, 335341.

[36] S. A. Mortazavi and J. D. Smart, J.Controlled Release 1993, 25, 197-203.

[37] F. J. O. Varum, F. Veiga, J. S. Sousa and A. W. Basit, Int. J. Pharm. 2011, 420, 11-19.

Figure 1. A strategy based on electrospun core-shell fibers for effective delivery of Gd(DTPA) to image the colon.

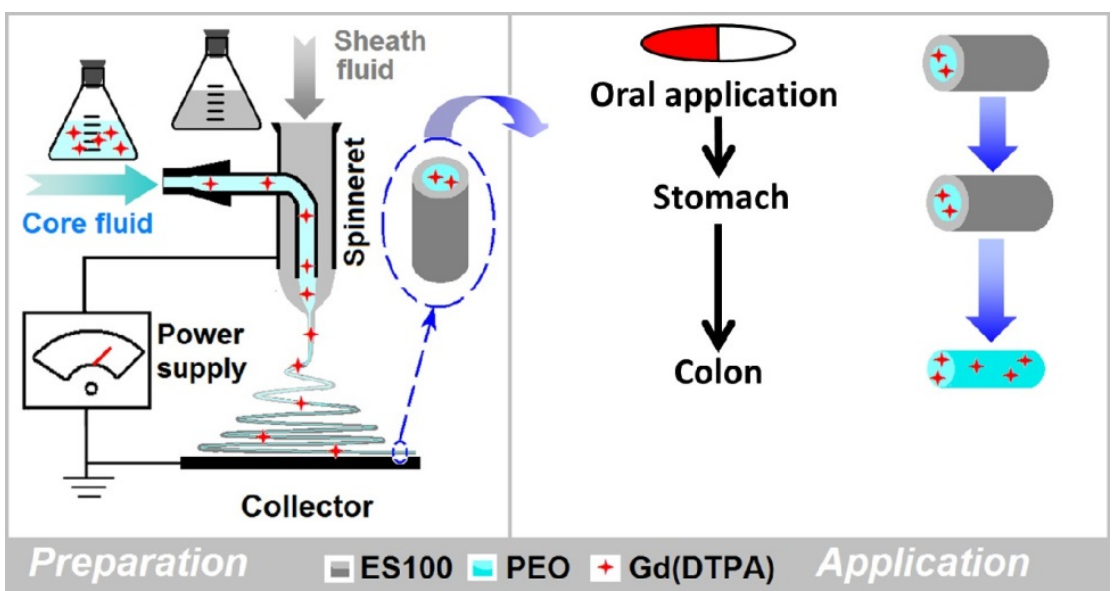

Figure 2. SEM images of the core-shell fibers. (a) F1; (b) F2; (c) F3; (d) F4; (e) F5; (f) F6; (g) F7; (h) F8; (i) F9; (j) the variation of fiber diameter with PEO molecular weight; and, (k) the fiber diameter of PEO $1 \mathrm{M}$ fibers as a function of Gd(DTPA) content.
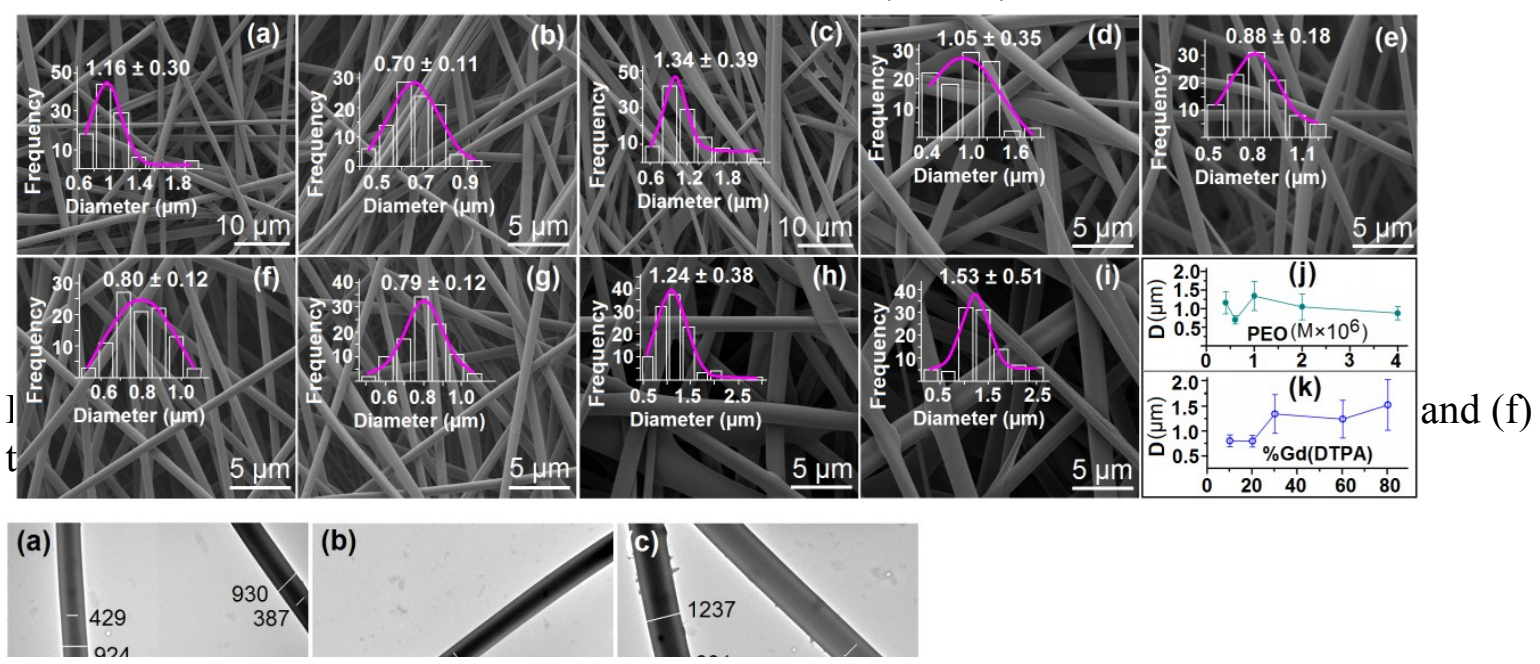
Figure 4. Results obtained using the F10 fibers. (a) SEM and (b) TEM images of F10; (c) the mucoadhesive properties of PEO1M fibers and F10 (control: blank colon); (d) a photograph taken under UV light showing the presence of rhodamine B on the surface of the mucosa after exposure to different $\mathrm{pH}$ milieu.

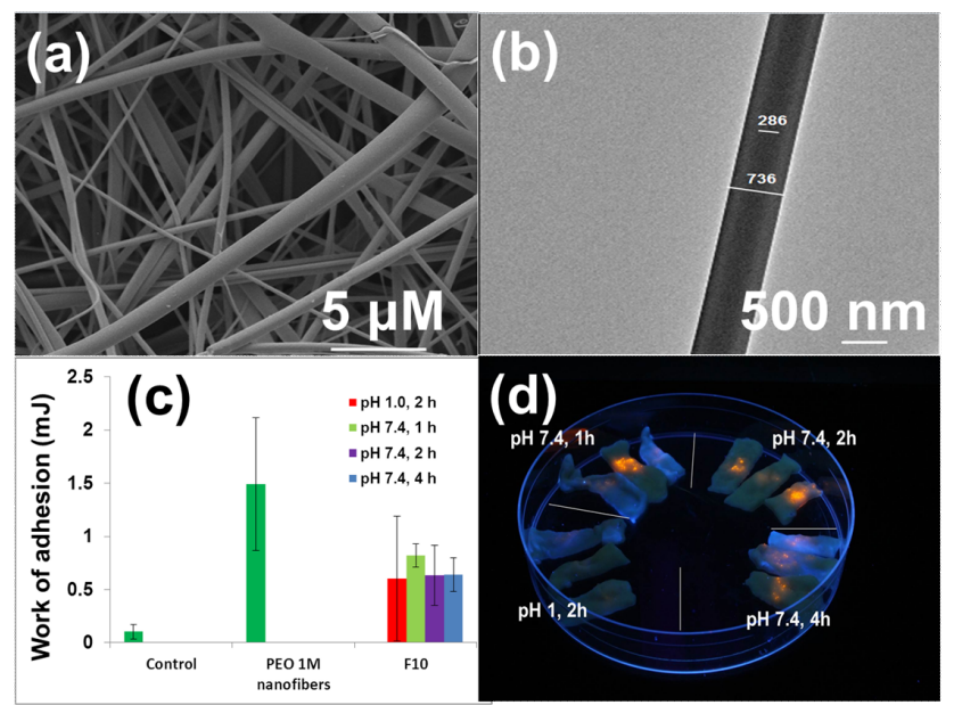


Figure 5. Photographs taken under UV light showing imaging of the porcine colon by F10. Fibers were immersed in PBS for 1 or $2 \mathrm{~h}$, and then either dried before being transferred to the colon or directly transferred while still wet. Images for dried fibers are given in (a), and for wet fibers in (b). In each image, the central column (control) is where a 50 ppm rhodamine B solution was added to the colon, while the left and right columns show results obtained after the fibers were placed in PBS buffer for 1 and $2 \mathrm{~h}$ respectively.

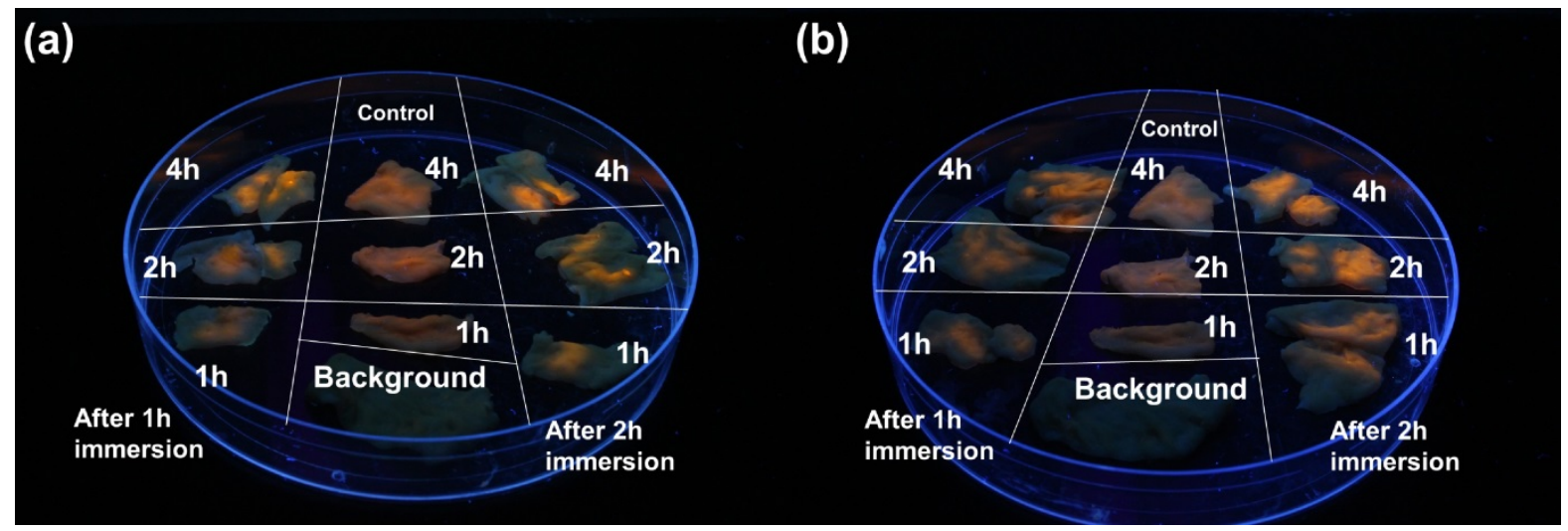

Table 1. Details of the coaxial electrospinning processes. The shell fluid comprised a $13.5 \%$ w/v solution of Eudragit S100 ethanol/DMAc $(8: 2 \mathrm{v} / \mathrm{v})$. The flow rates of the shell and core fluids were 1.5 and $0.3 \mathrm{ml} \mathrm{h}^{-1}$ respectively.

\begin{tabular}{|c|c|c|c|}
\hline \multirow{2}{*}{ No. } & \multicolumn{2}{|l|}{ Core fluid } & \multirow{2}{*}{ Objective } \\
\hline & Conc of matrix $(\mathrm{w} / \mathrm{v})^{\mathrm{a}}$ & Conc. of active ingredient ( $\%)$ & \\
\hline F1 & $3.5 \% \mathrm{PEO} 0.4 \mathrm{M}$ & $1.05 \% \mathrm{Gd}(\mathrm{DTPA})$ & \multirow{5}{*}{$\begin{array}{l}\text { Investigating the influence of } \\
\text { core polymer matrix on the } \\
\text { core-shell structure }\end{array}$} \\
\hline $\mathrm{F} 2$ & $3 \%$ PEO0.6M & $0.90 \% \mathrm{Gd}(\mathrm{DTPA})$ & \\
\hline F3 & $2 \%$ PEO1M & $0.60 \% \mathrm{Gd}(\mathrm{DTPA})$ & \\
\hline F4 & $1.5 \%$ PEO2M & $0.45 \% \mathrm{Gd}(\mathrm{DTPA})$ & \\
\hline F5 & $0.7 \%$ PEO $4 \mathrm{M}$ & $0.21 \% \mathrm{Gd}(\mathrm{DTPA})$ & \\
\hline F6 & $2 \%$ PEO1M & $0.2 \% \operatorname{Gd}(\mathrm{DTPA})$ & \multirow{4}{*}{$\begin{array}{l}\text { Investigating of the loading } \\
\text { of active ingredient on the } \\
\text { core-shell structure }\end{array}$} \\
\hline F7 & $2 \% \mathrm{PEO} 1 \mathrm{M}$ & $0.4 \%$ Gd(DTPA) & \\
\hline F8 & $2 \% \mathrm{PEO} 1 \mathrm{M}$ & $1.2 \% \operatorname{Gd}(\mathrm{DTPA})$ & \\
\hline F9 & $2 \% \mathrm{PEO} 1 \mathrm{M}$ & $1.6 \% \operatorname{Gd}(\mathrm{DTPA})$ & \\
\hline F10 & 2\% PEO1M & $0.6 \%$ Rhodamine B & $\begin{array}{l}\text { Release experiments, } \\
\text { mucoadhesion and imaging }\end{array}$ \\
\hline F11 & $3.5 \%$ PEO0.4M & $1.05 \%$ Rhodamine B & \multirow{4}{*}{ Mucoadhesion and imaging } \\
\hline F12 & $3 \%$ PEO0.6M & $0.90 \%$ Rhodamine B & \\
\hline F13 & $1.5 \%$ PEO $2 \mathrm{M}$ & $0.45 \%$ Rhodamine B & \\
\hline F14 & $0.7 \%$ PEO $4 \mathrm{M}$ & $0.21 \%$ Rhodamine B & \\
\hline
\end{tabular}

${ }^{a}$ PEOXM refers to PEO with an average molecular weight of $\mathrm{X} \times 10^{6} \mathrm{~g} / \mathrm{mol}$; e.g. PEO0.4M used $0.4 \times 10^{6} \mathrm{~g} / \mathrm{mol}$ PEO. 
Table 2. Proton relaxivity values in PBS $\left(20 \mathrm{MHz}, 37^{\circ} \mathrm{C}\right)$. Results are reported as mean $\pm \mathrm{SD}$, $\mathrm{n}=3$.

\begin{tabular}{llllll}
\hline Sample & $\begin{array}{l}{[\mathrm{Gd}]} \\
\mathrm{mM}\end{array}$ & $\begin{array}{l}T_{1} \\
\mathrm{~ms}\end{array}$ & $\begin{array}{l}T_{2} \\
\mathrm{~ms}\end{array}$ & $\begin{array}{l}r_{1} \\
\mathrm{~s}^{-1} \mathrm{mM}^{-1}\end{array}$ & $\begin{array}{l}r_{2} \\
\mathrm{~s}^{-1} \mathrm{mM}^{-1}\end{array}$ \\
\hline Gd(DTPA) in water & 1.00 & $226.20 \pm 1.91$ & $209.46 \pm 2.48$ & $4.42 \pm 0.04$ & $4.77 \pm 0.06$ \\
Gd(DTPA) in PBS & 1.00 & $244.50 \pm 1.06$ & $214.05 \pm 3.10$ & $4.09 \pm 0.02$ & $4.67 \pm 0.07$ \\
Gd(DTPA)+PEO $^{\mathrm{a}}$ & 1.00 & $263.40 \pm 0.20$ & $230.75 \pm 1.80$ & $3.80 \pm 0.01$ & $4.33 \pm 0.07$ \\
Gd(DTPA)+PEO+ $^{\text {Eudragit }}$ & 1.00 & $255.40 \pm 1.16$ & $200.00 \pm 0.91$ & $3.92 \pm 0.04$ & $5.00 \pm 0.11$ \\
Monolithic PEO1M & & & & & \\
loaded with & 1.00 & $250.00 \pm 1.00$ & $220.40 \pm 0.93$ & $4.00 \pm 0.02$ & $4.50 \pm 0.02$ \\
Gd(DTPA) & & & & & \\
F1 & 1.00 & $335.00 \pm 8.49$ & $232.20 \pm 4.38$ & $2.99 \pm 0.08$ & $4.31 \pm 0.08$ \\
F2 & 1.02 & $257.20 \pm 2.55$ & $151.33 \pm 1.09$ & $3.81 \pm 0.04$ & $6.48 \pm 0.05$ \\
F3 & 0.52 & $443.00 \pm 1.00$ & $265.93 \pm 5.51$ & $4.34 \pm 0.01$ & $7.23 \pm 0.15$ \\
F4 & 0.75 & $349.33 \pm 1.15$ & $212.80 \pm 6.65$ & $3.82 \pm 0.01$ & $6.27 \pm 0.20$ \\
F5 & 0.76 & $286.00 \pm 2.00$ & $200.27 \pm 1.50$ & $4.60 \pm 0.03$ & $6.57 \pm 0.05$ \\
F6 & 0.25 & $619.00 \pm 4.58$ & $330.67 \pm 9.02$ & $6.46 \pm 0.05$ & $12.10 \pm 0.33$ \\
F7 & 0.49 & $359.00 \pm 1.00$ & $200.73 \pm 4.25$ & $5.68 \pm 0.01$ & $10.17 \pm 0.22$ \\
F8 & 1.02 & $274.00 \pm 2.65$ & $167.87 \pm 2.10$ & $3.58 \pm 0.03$ & $5.84 \pm 0.07$ \\
F9 & 1.01 & $318.00 \pm 1.00$ & $249.83 \pm 3.61$ & $3.11 \pm 0.01$ & $3.96 \pm 0.06$ \\
Mean (F1-F9) & & & & $4.27 \pm 1.16$ & $6.99 \pm 2.62$ \\
\hline
\end{tabular}

${ }^{a}$ Physical mixtures

Table 3. Proton relaxivities recorded in tris buffer $\left(20 \mathrm{MHz}, 37^{\circ} \mathrm{C}\right)$. Results are reported as mean $\pm \mathrm{SD}, \mathrm{n}=3$.

\begin{tabular}{|c|c|c|c|c|c|}
\hline Sample & $\begin{array}{l}{[\mathrm{Gd}]} \\
\mathrm{mM}\end{array}$ & $\begin{array}{l}T_{1} \\
\mathrm{~ms}\end{array}$ & $\begin{array}{l}T_{2} \\
\mathrm{~ms}\end{array}$ & $\begin{array}{l}r_{1} \\
\mathrm{~s}^{-1} \mathrm{mM}^{-1}\end{array}$ & $\begin{array}{l}r_{2} \\
\mathrm{~s}^{-1} \mathrm{mM}^{-1}\end{array}$ \\
\hline $\mathrm{Gd}(\mathrm{DTPA})$ in water & 1.00 & $228.65 \pm 0.49$ & $206.06 \pm 1.78$ & $4.37 \pm 0.01$ & $4.85 \pm 0.04$ \\
\hline Gd(DTPA) in PBS & 1.00 & $225.85 \pm 0.07$ & $202.83 \pm 2.01$ & $4.43 \pm 0.00$ & $4.93 \pm 0.05$ \\
\hline Gd(DTPA) + PEO $^{\mathrm{a}}$ & 1.00 & $143.40 \pm 0.95$ & $121.96 \pm 0.60$ & $6.97 \pm 0.05$ & $8.20 \pm 0.04$ \\
\hline $\begin{array}{l}\text { Gd(DTPA)+PEO+ } \\
\text { Eudragit }^{\mathrm{a}}\end{array}$ & 1.00 & $229.00 \pm 1.41$ & $208.90 \pm 1.98$ & $4.37 \pm 0.03$ & $4.79 \pm 0.05$ \\
\hline F1 & 0.77 & $145.93 \pm 0.35$ & $123.07 \pm 0.70$ & $8.90 \pm 0.02$ & $10.55 \pm 0.06$ \\
\hline F2 & 0.93 & $174.33 \pm 0.67$ & $114.90 \pm 1.17$ & $6.17 \pm 0.02$ & $9.36 \pm 0.10$ \\
\hline F3 & 0.46 & $202.00 \pm 0.00$ & $154.50 \pm 2.16$ & $10.76 \pm 0.00$ & $14.07 \pm 0.20$ \\
\hline F4 & 0.71 & $158.90 \pm 0.78$ & $110.69 \pm 0.62$ & $8.86 \pm 0.04$ & $12.72 \pm 0.07$ \\
\hline F5 & 0.76 & $122.77 \pm 0.46$ & $87.52 \pm 0.49$ & $10.72 \pm 0.04$ & $15.03 \pm 0.08$ \\
\hline F6 & 0.25 & $413.67 \pm 0.58$ & $233.23 \pm 3.51$ & $9.67 \pm 0.01$ & $17.15 \pm 0.26$ \\
\hline F7 & 0.49 & $166.03 \pm 0.32$ & $109.23 \pm 1.39$ & $12.29 \pm 0.02$ & $18.68 \pm 0.24$ \\
\hline F8 & 1.09 & $139.00 \pm 0.78$ & $111.37 \pm 0.64$ & $6.60 \pm 0.04$ & $8.24 \pm 0.05$ \\
\hline F9 & 1.08 & $160.47 \pm 0.58$ & $139.85 \pm 0.97$ & $5.77 \pm 0.02$ & $6.62 \pm 0.05$ \\
\hline Mean (F1-F9) & & & & $8.86 \pm 2.27$ & $12.49 \pm 4.11$ \\
\hline
\end{tabular}

${ }^{\mathrm{a}}$ Physical mixtures 